\title{
Notes on the vocalizations of Chestnut-winged Babbler (Stachyris erythroptera)
}

Peter Boesman

In the following we briefly analyze and compare voice of the different races of Chestnutwinged Babbler (Stachyris erythroptera). We also try to quantify the extent of any vocal differences using the criteria proposed by Tobias et al. (2010), as a support for taxonomic review. We have made use of sound recordings available on-line from Xeno Canto (XC).

Song of all races is a series of low-pitched bubbling notes, with variable pace. Some examples:

Peninsular Malaysia:

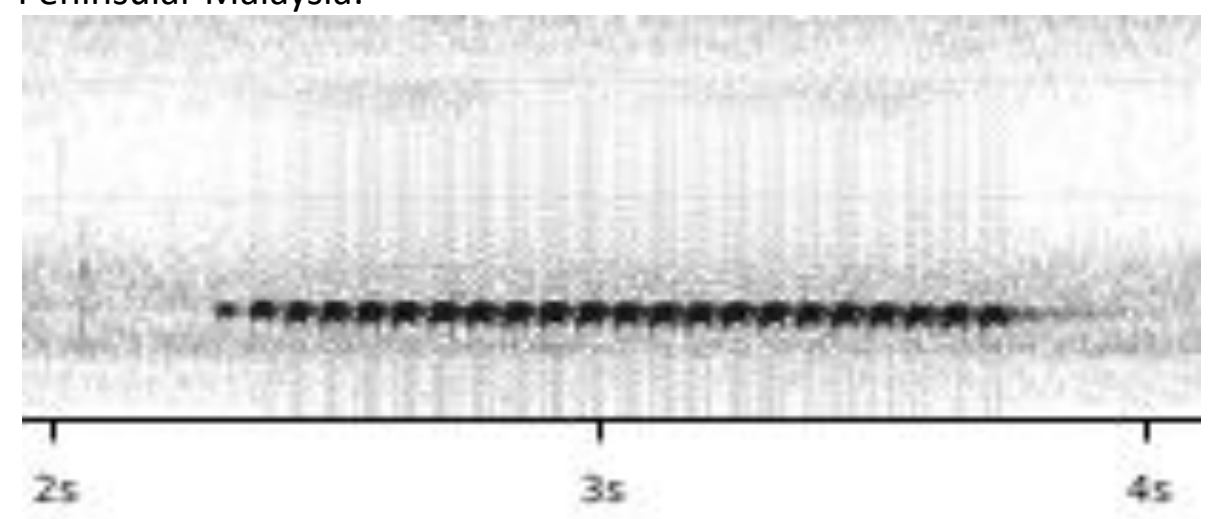

Sumatra:

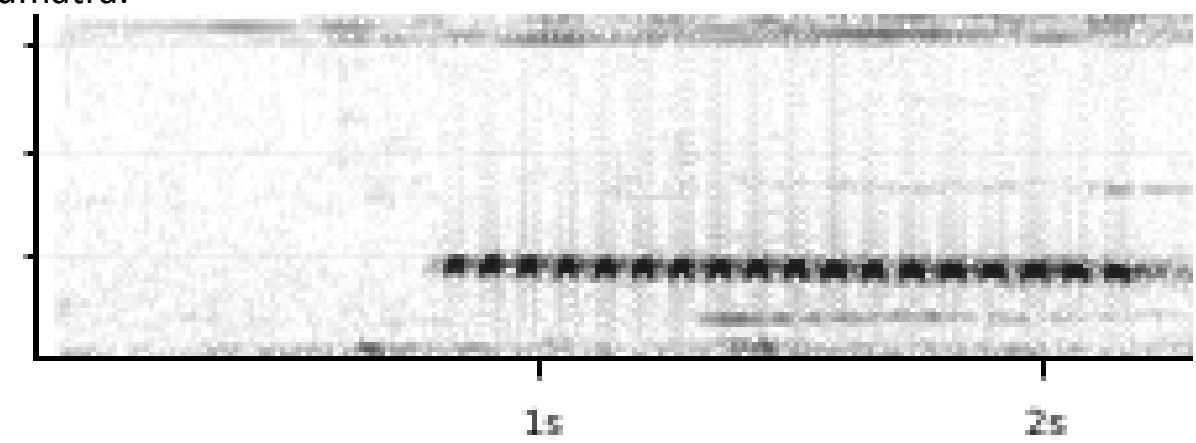

Borneo

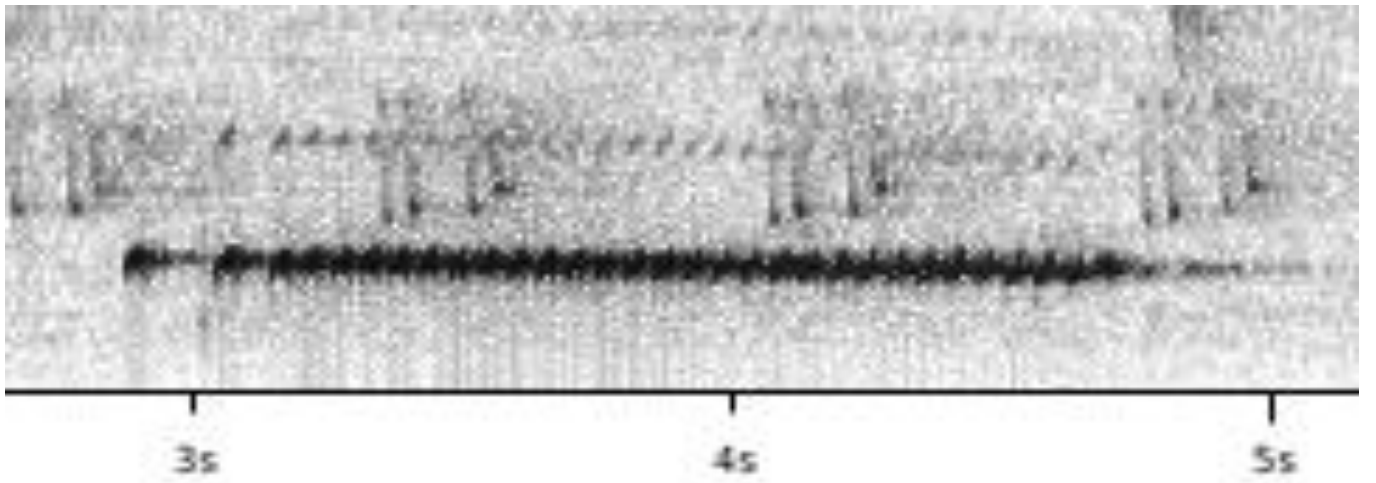



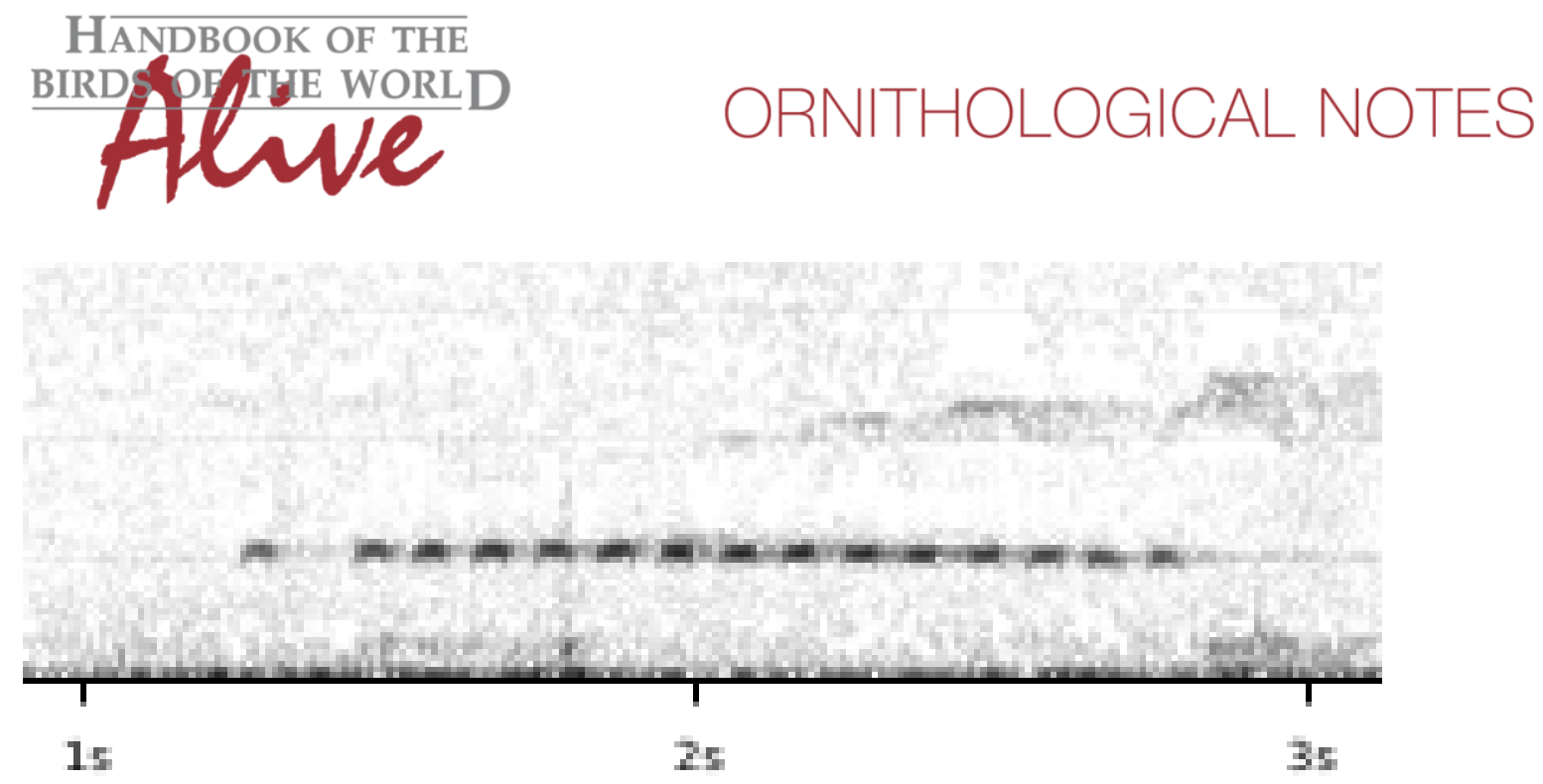

The only difference we could find after checking some 50 recordings distributed over the entire range, is that birds from Borneo typically start the song with a single note separated by a pause from the longer series, while none of the recordings from peninsular Malaysia and Sumatra shows this feature (occassionally in Bornean birds, typically in duet, one of the two birds may omit this first separated note. The difference might thus be only apparent in male song).

We have here thus a clear measurable vocal difference. The few available recordings of rufa from S Borneo also show this feature. A grouping to quantify vocal differences should thus be bicolor/rufa vs. other races. In this case, one could quantify differences by e.g. length of first pause or ratio first/second pause. This would lead to a vocal score of about 3.

This note was finalized on 8th April 2016, using sound recordings available on-line at that moment. We would like to thank in particular the sound recordists who placed their recordings for this species on XC: Patrik Åberg, Marc Anderson, Peter Boesman, Tjalle Boorsma, Romas Carlberg, Eric Cannizzaro, Mike Catsis, Stijn Cooleman, Brian Cox, Niels Poul Dreyer, David Edwards, Qin Huang, Greg Irving, Frank Lambert, John V Moore, Mike Nelson and Arend Wassink.

\section{References}

Tobias, J.A., Seddon, N., Spottiswoode, C.N., Pilgrim, J.D., Fishpool, L.D.C. \& Collar, N.J. (2010). Quantitative criteria for species delimitation. Ibis 152(4): 724-746.

\section{Recommended citation}

Boesman, P. (2016). Notes on the vocalizations of Chestnut-winged Babbler (Stachyris erythroptera). HBW Alive Ornithological Note 267. In: Handbook of the Birds of the World Alive. Lynx Edicions, Barcelona. (retrieved from http://www.hbw.com/node/1251708 on 5 October 2016). 
HANDBOOK OF THE

BIRDŚPF THE WORLD

ORNITHOLOGICAL NOTES

3 